\title{
Research on Several Basic Problems in Low Carbon Travel in China ${ }^{1}$
}

\author{
Hu Xiaoling ${ }^{a}$, Liu $\mathrm{Na}^{\mathrm{b}}$, Liu Ting ${ }^{\mathrm{c}}$
}

${ }^{a}$ College of Management,Wuhan Technology and Business University,Wuhan,430065, China

${ }^{\mathrm{b}}$ Hubei Business Service Research Development Center,Wuhan Technology and Business University, Wuhan, 430065,China

${ }^{c}$ College of Resources and Environmental Sciences, Hunan Normal University, Changsha, 410081 ,China

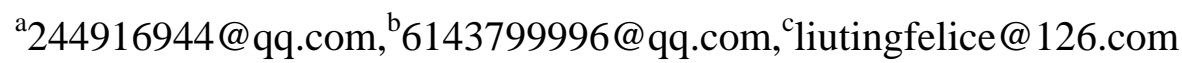

Keywords: Tourism Enterprise; Low- carbon Tourism; Theoretical Study

Abstract: With the development of low-carbon tourism, economic theory applied to traditional tourism was suffering a strong challenge. In this paper, we put forward some views about what low-carbon tourism is, how to develop low-carbon tour in tourism enterprises, how to blossom low-carbon tourism, and how to encourage tourism enterprises to develop ecotourism and other related issues. This article is aimed at establishing some theoretical framework used to study the issues pertaining to low-carbon tourism, promote the consciousness of low-carbon tourism enterprises in particular, and develop low-carbon tourism.

\section{What is low-carbon tourism?}

Since the industrial revolution, with the rapid development of the world economy, the human's material wealth has been greatly enriched, but this has also been conducive to depletion of resources, and environmental pollution. This is not only a matter of science, but also is a political, economic and social problem. In order to respond positively to the more serious environmental problems faced nowadays, the British government released the energy white paper in 2003, predicting "our energy future: to create a low-carbon economy." For the first time the "low-carbon economy" concept was put forward, which gained tremendous attention and positive response from the international community. Compared with the traditional economic development model, low-carbon economy is of a low energy consumption, low pollution, low emission-based economic development model (Zhang Kunmin, 2008). This economic development model is generally considered to be the only way for countries to achieve sustainable socio-economic development. Thus, the 2009 World Economic Forum put forward the "low-carbon tourism" as a new concept. To this end, this article is about low-carbon tourism, shedding some light on how tourism enterprises develop low-carbon tourism and how to promote tourism enterprises to develop low-carbon tourism so Regarding low-carbon tourism, scholars have different understanding of the so-called low-carbon tourism, but so far they have summed up the concept into three mainly points: First, low-carbon tourism is a green economic development model; that is, low energy consumption, low pollution, low-emissions-based economy. Second, low-carbon tourism is practiced through low-carbon technology, the implementation of carbon sink mechanism promoting low-carbon tourism consumption. In other words, the use of low-carbon technology, into the carbon sink mechanism promotes low-carbon consumption which, in turn, achieves low-carbon tourism development (Cai Meng, Wang Yuming, 2010; Zhuang Guiyang, 2011; Zheng Li, 2012). Third, the low-carbon tourism is a new concept of tourism. This implies that it is through a variety of ways

\footnotetext{
1 Hubei Provincial Department of Education research project "low-carbon tourism development path and mechanism of innovation research (16G146)" one of the phased results; Hubei Provincial Department of Education research project "the development of low-carbon tourism path and mechanism innovation research”(B2016336) one of the stage results; Hubei business Service Research development center project funding (2016Y06) one of the stage results.
} 
and personalized system thathe economic development of new tourism and management concepts are achieved (Huang Wensheng, 2009; Hou Wenliang, 2010; Chen Haibo, 2011). However, we believe that, no matter how we define the term in question, we should take the following characteristics of low-carbon tourism into consideration:

(1) economy. That is, the way how tourism fosters intensive changes, the use of low-carbon technologies and measures to reduce the cost of tourism products as well as reduce the energy waste. Low-carbon tourism economy is also reflected in the price of tourism products being featured as high-quality but bought in lower prices.

(2) externality. Externality refers to the behavior of an economic object having influences on the interests of other economic object, and that the subject, which imposes such effects does not pay any price or compensation (Meade, 1952) ${ }^{[1]}$. Externality can be divided into two elements: positive externalities and negative externalities. Positive externalities refer to the behavior of an economic subject toward other economic object bringing additional benefits, of which the beneficiaries do not have to pay any price; by contrast, negative externalities refer to the behavior of an economic entity toward other economic entities carrying additional losses, while the tourism enterprises does not pay (Viner, 1931) ${ }^{[2]}$. Within the process of the development of low-carbon tourism, two externalities have appeared. By developing low-carbon tourism, tourism enterprises bring benefits to the community, which cannot be compensated, hence the existence of positive externalities; on the contrary, if companies ignore low-carbon tourism without bearing the cost, they engender losses to the community, which constitutes negative externalities. Both the externalities can affect the development of low-carbon tourism. Positive externality can damage the enthusiasm of tourism enterprises to develop low-carbon tourism and reduce investment in low-carbon tourism, while negative externalities are not only economically ineffective, but are also adept at aggravating the environmental pollution of tourism enterprises.

(3) cultural. On the one hand, low-carbon tourism protects culture; on the other hand, the process of being formed low-carbon tourism culture. In the planning and design of tourism destination, the low carbon culture should be strengthened, ecological civilization and other tourist attraction should be protected. The cultural charm of tourism destination is the source of the low carbon tourism attraction. With the formation of raw materials in low-carbon tourism culture, tourism destination will heighten the cultural and ecological charm.

(4) institutional. The institutional factors have some influence on the development of low-carbon tourism. These factors take into account the tax policy, financial subsidy, credit policy, legal system, marketization degree, public opinion and other institutional aspects that have a positive impact on low-carbon tourism.

(5) high quality. That is, establishing low-carbon economy through the use of some carbon technology to enhance the quality of tourism products. With this practice, low-carbon tourism will also bring the quality of tourism products needed through the improvement of hardware and software services for low-carbon tourists. Such services are expected to provide healthy, scientific and efficient tourism products to meet the needs of different low-carbon tourists for low-carbon tourism with high quality.

(6) comprehensive. A comprehensive low-carbon tourism is reflected in the production and consumption in two ways. In terms of production, low-carbon tourism extends the industrial chain of tourism such as transportation, hotels, attractions, and entertainment through low-carbon technologies, new energy development, etc. In terms of consumption, multiple production entities provided products and services for low-carbon tourists. Therefore, low-carbon tourism has a comprehensive characteristic.

\section{How tourism enterprises develop low-carbon tourism contents}

Developing low-carbon tourism, tourism enterprises aim at strengthening the management of low-carbon tourism. Should that be the case, the content needs to include, at least, the following three aspects: 


\subsection{Strategic management based on low-carbon tourism}

That is, low-carbon tourism should be included in the strategic management of tourism enterprises. Tang Chengcai (2011) proposed that tourism enterprises actively use clean energy and low-carbon materials technology, and strictly control the carbon emissions in the tourism process; develop a management system with operational, energy-saving and emission reduction responsibility and strengthen the carbon management; apply the rational development model of low-carbon tourism products, shaping low-carbon tourism culture; participate in tourism carbon and system construction, establishment a reasonable carbon and experience as well as certification system. Dagoumas AS, Barker TS (2010) proposed the macro-metering model E3MG. Based on the energy-economic-environment model, the analysis of the simulation scenario shows that the energy saving and emission reduction targets can be achieved through different channels, and can effectively promote the national Macroeconomic development ${ }^{[3]}$. Thus, it can be seen that, to develop low-carbon tourism strategic management, tourism enterprises should pay attention to the following five aspects: first, to improve the tourism enterprises, the awareness of how to develop low-carbon tourism recognition degree is essential; second, tourism enterprises should know how to develop low-carbon tourism to resources and support; third, tourism enterprises can enhance the performance of the tourism enterprises by developing the low-carbon tourism awareness; fourth, tourism enterprises are able to develop low-carbon tourism; fifth, adaption to low-carbon tourism needs changes in social issues in order to seize the development of low-carbon tourism opportunities. Therefore, with the development of tourism enterprises, the strategic management of tourism enterprises is integrated into the strategic management of low-carbon tourism.

2.2 Daily control based on low-carbon tourism

It is of great importance that low-carbon tourism is integrated into the daily business of tourism enterprises control. In the aspect of business control, the tourism enterprises establish internal control system, including the quality of service and energy saving of low-carbon tourism products in the service process of tourism enterprises. In reference to budget control, the budget of tourism enterprises should be included in the daily control activities. As regards accounting control, tourism enterprises ought to establish a system to disclose environmental information; in terms of financial control, consideration needs to be given to the tourism investment, staff working environment, energy-saving materials production products and so on. There is no doubt that all of these aspects of business management are crucial to tourism enterprises to develop low-carbon tourism strategy specific, thereafter the development of low-tourism tourism enterprises can be implemented.

\subsection{Performance evaluation based on low-carbon tourism}

This involves fitting low-carbon tourism into performance evaluation of tourism enterprises. Low carbon tourism evaluation index system has a destination for tourism resources and environment, tourism enterprises of low carbon service environment, community and tourism consumer awareness, as well as tourism management of four categories of indicators. Therefore, these aspects are to be considered in the evaluation of the performance of tourism enterprises. Only in this way can we have a comprehensive evaluation of the sustainable development of tourism enterprises. Otherwise, the value of some enterprises may be underestimated, and the existence of crisis in tourism enterprises is not detectable. Wu Xiaoshan (2011) called our attention to the following questions regarding the important aspects of low-carbon tourism development of a comprehensive evaluation: first, what is the tourism resources destination and environmental indicators? Second, what is the low-carbon tourism business environment like? Third, what is the degree of community tourism consumer awareness? Four, which tourism administrations will not respond to certain kind of implementation strategy? Boemi S.N., Slini T et al. (2011) said that the hotel building energy efficiency and environmental performance in its energy-saving emission reduction plays a vital role; and the development of a set of hotel energy efficiency and environmental protection have to pass through some evaluation indicators ${ }^{[4]}$. Tanaya Mohanty (2011) argues that through the development of farms and forests, it is important to focus on the carbon sinks of farms and forests in the development of low-carbon economies, which can effectively control the greenhouse gases in the atmosphere ${ }^{[5]}$. In short, in the evaluation of tourism 
enterprise performance, from the perspective of low-carbon tourism design evaluation indicators, it is essential to evaluate the realization of low-carbon tourism in tourism enterprises.

\section{How to promote tourism enterprises to develop low-carbon tourism}

3.1 Promoting low development of low-tourism tourism enterprises, the key success lies in the establishment of low-carbon tourism development and appropriate corporate governance mechanism. The governance mechanism of tourism enterprise includes two parts: internal governance mechanism and external governance mechanism. In the tourism enterprise, internal governance mechanism should be proceeded from the following aspects:

(1) Perfecting the common decision-making mechanism. That is, tourism enterprises, including travel agencies, tourism hotels, tourism transportation, through institutional arrangements, should ensure that tourism enterprises develop low-carbon tourism. To this end, to develop the low-carbon tourism, tourism enterprises can establish a decision-making mechanism: First, the establishment of a system of operability and conservation responsibility system such as, the preparation of low-carbon tourism travel brochures, tourist guides, operator manuals, etc.; second, the development of low-carbon tourism products such as tourism hotels using new energy-saving equipment, to promote green food and organic food as well as the use of public transport, etc.; third, establish carbon, experience and certification system. Guide visitors to participate in carbon neutral experience and certification; cultivate low-carbon lifestyle, the preparation of low-carbon tourism planning, and promote low-carbon tourism.

(2) Perfecting the common monitoring mechanism. In tourism enterprises, this can be exercised through the promotion of education to improve the appropriate monitoring mechanism. Through the development of low-carbon tourism, certification, carbon sequestration, carbon trading, low-carbon consumption, improve the common monitoring mechanism. Tourists guides of low-carbon tourism consumption should promote tourism enterprises' clear responsibility, which is conducive to the development of low-carbon tourism. To this end, perfect the above common decision-making mechanism, clear government and tourism industry departments in charge of the main responsibility. In other words, the understanding of low-carbon tourism, low-carbon lifestyle advocacy, the protection of the ecological environment and so on are to be considered. In addition, a lot of low-carbon tourism projects publicity and education along with supervision of tourists' low-carbon lifestyle are required.

(3) Perfecting the common camera management mechanism. That is, tourism enterprises running through incentives and low-carbon tourism stakeholders need to adjust the formation of low-carbon tourism development efforts. Low-carbon tourism stakeholders should include governments, tourism managers, local residents, and tourists on the list. The role of low-carbon tourism stakeholders is: for the government, holding the responsibility and power to encourage participation in low-carbon tourism, and optimize the decision-making mechanism; for tourism managers, letting tourism managers realize that low-carbon tourism is conducive to increased competitiveness; for local residents, obtaining the benefits through carbon sinks and carbon trading market; for tourists, stimulating tourists' participation in low-carbon tourism.

3.2 In the tourism enterprise, external governance mechanism should be improved from several aspects.

(1) The government's low-carbon guide

Government departments are the guide and coordinator of low-carbon tourism. At present, the Chinese government has played an important and positive role in this regard, but there are also some problems, such as the one-sided pursuit of GDP, regardless of environmental pollution; functional cross, power and responsibility are unknown, which leads to mutual prevarication or repeated intervention. To solve these problems, we need to improve the government regulation mechanism from the following aspects:

(1) To develop low-carbon tourism-related series of standard specifications and to establish some effective environmental protection laws and regulations that cover the area from low-carbon 
tourism to legal protection. Assuming their responsibility, the government unified the national low-carbon tourism laws to develop low-carbon tourism demonstration sites. In their turn, tourist hotels and tourist attractions focus on low-carbon tourism, strengthen low-carbon construction and management. (2) Establishment of low-carbon tourism development policies and special funds. First, the development of low-carbon tourism enterprises can foster the development of fiscal and taxation policy. This way, for example, government departments can collect carbon taxes and cultivate carbon sinks market. Besides, the establishment of low-carbon tourism special funds, green credit and other economic means can be accountable for low-carbon tourism policy protection. Second, financial subsidies protect the low-carbon tourist hotels and tourism traffic. (3) Establishment of low-carbon tourism management agencies. This can take into consideration the construction of low-carbon tourism development certification, the development of carbon sequestration carbon trading, low-carbon tourism and other systems. The responsibilities of the agencies are to establish carbon emission audit access mechanism and standards, to carry out "low-carbon certification" to strengthen the low-carbon tourism enterprises and attractions assessment and management, and gradually cultivate carbon sink mechanism.

(2) Low-carbon operation of tourism enterprises

Tourism enterprises should include tourism hotels, travel agencies, tourism and transportation. Tourism enterprises are the core of low-carbon tourism practice, and they are the main body of carbon emissions in tourism activities. (1) Tourism enterprises are expected to adhere to low-carbon development ideas, the use of clean energy from the construction level control of tourism enterprises carbon emissions. For example, tourism hotels promote solar energy, biomass and other clean energy. (2) Tourism enterprises can improve the energy-saving emission reduction capacity. For example, travel agencies use electronic information technology to innovate cultural and educational tourism activities for carbon-compensated tourism activities. Tourism hotels use new energy technologies to reduce energy consumption, reduce pollutant generation and emissions, promote low-carbon foods and hold low-carbon activities to build green eco-hotels. Tourism traffic need to promote pollution-free means of transport, to guide tourists to use public transport, such as buses, trains, ships and other carbon emissions of low transport vehicles to reduce carbon emissions ${ }^{[6]}$. (3) Tourism enterprises are also able to strengthen low-carbon tourism services. On the one hand, they have the ability to engage in the construction of tourism industry's low-carbon service quality system, development of low-carbon tourism service quality standards, quality of service testing system and service quality supervision system. On the other hand, abundant low-carbon tourism services and increase the low-carbon tourism publicity are seen as display and advisory services enhancing public awareness of low-carbon tourism development. In addition, there seem to exist the promotion of tourism electronic information service system, the reaction area of passenger information, traffic information and accommodation information.

(3) Consumer low-carbon cultivation

Tourists, as a low-carbon tourism development experience, should reduce the carbon footprint and choose low-carbon lifestyle of three dimensions. (1) To strengthen low-carbon consumer awareness. Tourists are fully aware of the importance of environmental protection, energy saving, and reduction of carbon footprint. (2) To change the way people travel. Tourists choose high-speed railways, railways and highways, subways, buses and other low-carbon travel. Tourists are using environmentally friendly cars, walking and cycling. Tourists can choose non-polluting, low-emission vehicles. (3) Implementation of low-carbon tourism consumption. Examples of these are the choice of eco-restaurant, servings of green vegetables and organic vegetables which reduce carbon emissions and control the consumption of green food. Choosing environmentally friendly, eco-type hotel, water-saving as little as possible with the hotel's disposable supplies can also be helpful; prepare items for life.

(4) Establishment of low-carbon tourist attractions

Low-carbon tourist attractions are the main body of low-carbon tourism products, low-carbon tourist area promotion and implementation are a systematic project. Low-carbon tourist attractions 
have their own constructions of (the main) contents: (1) Scientific planning of low-carbon tourist attractions. Actively create low-carbon tourism attraction, strictly control the ecological capacity of scenic spots, and construction of the low-carbon tourism demonstration sites. The first one on the list is the fragile ecological environment; the second is the industrial and agricultural tourism demonstration sites; third is low-carbon consumer awareness of the region. (2) The use of new energy (solar energy, wind energy, geothermal energy), tourism information technology (tourism e-commerce) and electronic intelligence technology can improve the tourist attractions of the service facilities and energy conservation. (3) Innovation management system. Taking the tourism scene of low-carbon tourism as the core value, innovative management system is needed. To promote regional low-carbon economy through low-carbon tourism industry, building scenic interaction, contracting energy management model and building scenic alliance are of greatimportance.

\section{Conclusion}

This paper focuses on low-carbon tourism theory, discussing what the low-carbon tourism is, how tourism enterprises develop low-carbon tourism and how to promote the development of low-carbon tourism in tourism enterprises. It also argues several points: (1) Low-carbon tourism is a new change, based on a formal or informal system, for tourists, tourism enterprises, tourist destinations, tourist attractions and other low-emission, low pollution, low energy consumption of sustainable tourism development of an ecological civilization model. (2) the reason why tourism enterprises develop low-carbon tourism by strengthening management, including strategic management, daily control, performance management, etc. (3) The fact that, tourism enterprises must strengthen to management, including strategic management, daily control, performance management, etc. to develop low-carbon tourism; (4) the awareness that the development of low-carbon tourism by tourism enterprises must be established in compliance with the low-carbon tourism model to play the internal and external governance mechanism. These findings, not only help to establish a theoretical framework for the study of low-carbon tourism, but also, in practice, to help tourism enterprises to achieve low-carbon tourism.

Finally, it is necessary to point out that the purpose of this study, on the issue of low-carbon tourism, is not only to clarify these problems, but importantly to attract people's attention to these issues in order to play a role in the future. At present, like it is seen in China,some academic research on low-carbon tourism has achieved some theoretical results, but on the whole, the relevant research found so far has mainly been carried out to introduce the importance of low-carbon tourism for the sake of understanding and testing the importance of the stage. Therefore, there are many low-carbon tourism issues needed to be studied theoretically and given a clear answer.

\section{References}

[1] Meade J. E. External Economies and Diseconomies in Competitive Situation[J].The Economic Journal, 1952, (62):54-67.

[2] VinerJ.,Cost Curves and Supply Curves[J].Journal of Economic,1931(3):23-46.

[3] Dagoumas A.S.,Barker T.S. Pathways to a low-carbon economy for the UK with the macroeconometric E3MG model[J]. Energy Policy,2010 (38):6.

[4] Boemi S.N.,Slini T. et al. A Statistical Approach to the Prediction of the Energy Performance of Hotel Stock[J].International Journal of Ventilation,2011,40:18-23..

[5] Tanaya Mohanty. Harnessing Farms and Forests in the Low-Carbon Economy: How to Create, Measure, and Verify Greenhouse Gas Offeets[J]. Electronic Green Journa 1,2011,(31):2.

[6] Lin T Z P. Carbon dioxide emissions from transport in Taiwans national parks [J].Tourism Management ,2010,31(2):285-290. 